\section{Genesis of a high-tech hub}

\section{A century of philanthropy alongside military research has laid solid foundations for today's diverse sci-tech sector, says Chloe Veltman.}

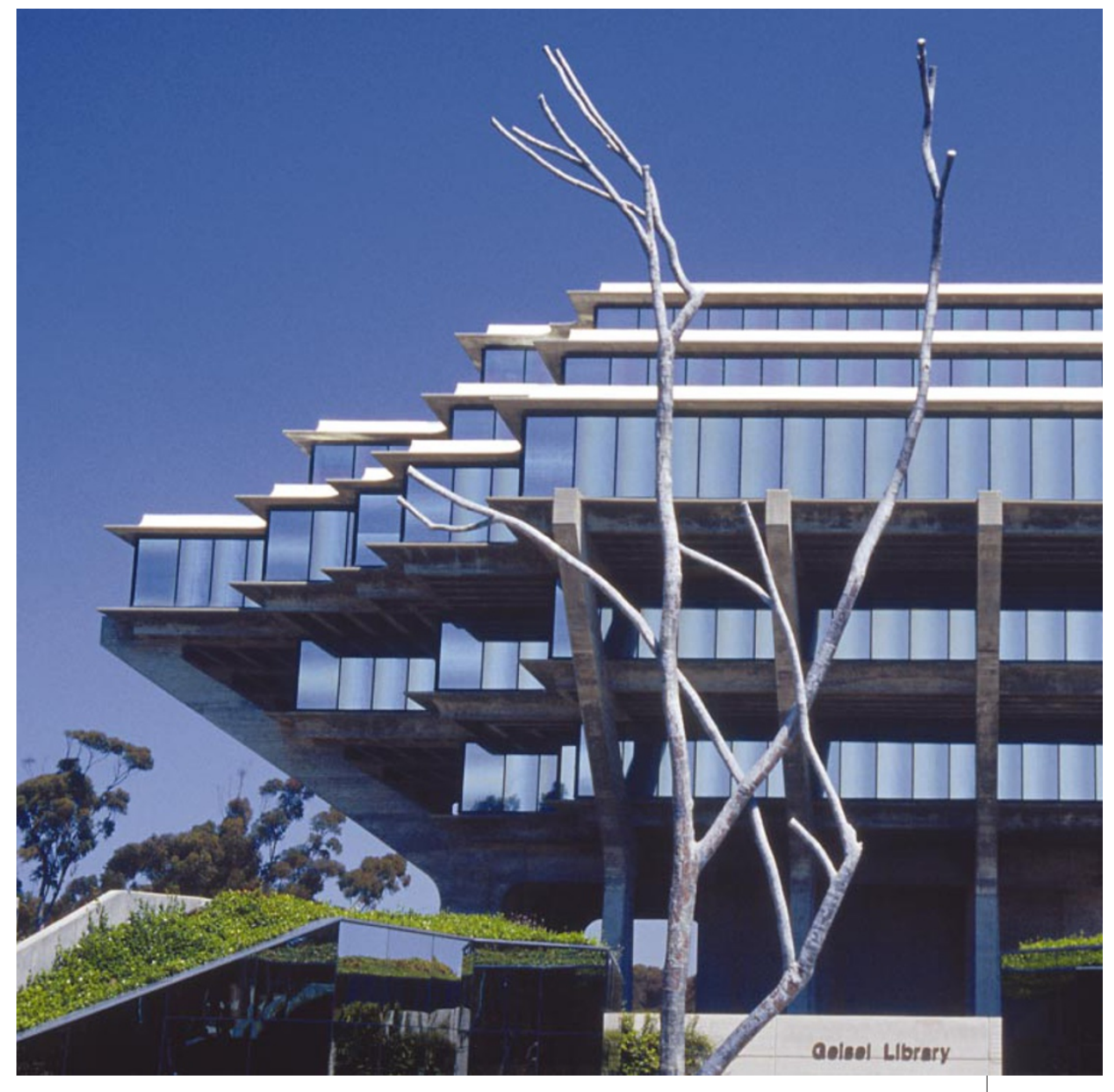

Mesa appeared in 1956, when the city gave defence company General Atomics (GA) 120 hectares of land on which to build a research centre. Keen to increase the high-tech presence in San Diego, city officials later designated the Mesa as a science and technology zone, allowing only high-tech organizations to build there. GA went on to spawn some 60 different science com- "City officials panies, including Sharp Laboratories and Science Applications International Corporation.

Long before GA arrived on the Mesa, San Diego had been priming itself to become a hightech centre. As early as 1903, when scientist William Ritter founded the Marine Biological Association of San Diego, the city had begun to attract a research community. With funding from a newspaper mogul, E.W. Scripps, Ritter's fledgling marine laboratory transformed itself in 1912 into the Scripps Institution of Oceanography, becoming part of the University of California.

But San Diego's transformation from a town so remote that it was initially bypassed by the railroad to one of the most networked places on Earth can be traced back to the militarization of its economy during the First World War. Hoping that a military presence would strengthen the economy, local government paid for the dredging of the harbour to accommodate navy ships. "As early as 1907, people saw an opportunity for economic growth tied to new technologies and emerging industries," says Mary Walshok, associate vice-chancellor for extended studies and public programmes at UCSD. With its non-stop sunshine and calm waters, the city soon became a favourite repository for federal defence dollars. Military facilities proliferated, bringing in a high concentration of new technologies, from long-distance radio transmission to amphibious warfare.

The military presence in San Diego proved a mixed blessing. Although healthy defence income helped lessen the blow of the Depression years and subsequent bust cycles for San Diego, and although the navy built the city's first sewage-treatment facility in 1943 and erected an aqueduct to ameliorate the area's severe water shortage, the price for the people of San Diego was high: by the Second World War, according to Mike Davis, a historian at the University of California, Irvine, San Diego had sacrificed more than a quarter of its land area to the military. 


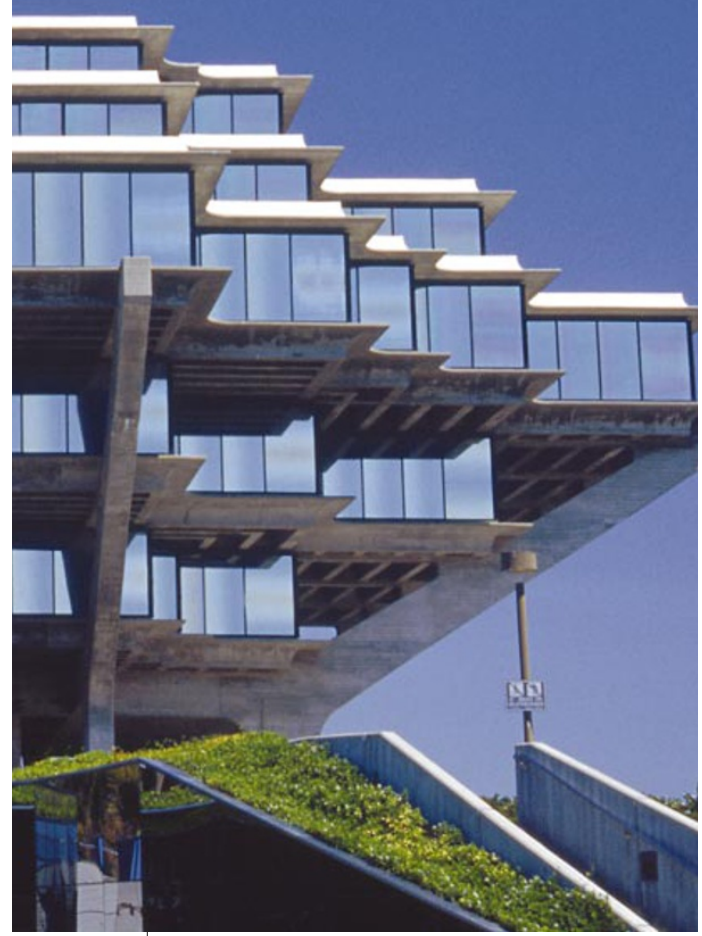

If the time was ripe for the city's science to diversify, it did not have long to wait. After the war, flush with defence dollars, Scripps Institution director Roger Revelle and GA founder John Jay Hopkins wanted to establish a world-class science and engineering graduate school in the area. Revelle even offered a handful of favoured scientists, later to become UCSD's founding faculty, laboratory space at Scripps.

\section{Teething troubles}

To launch UCSD, Revelle and Hopkins had to fight a protracted battle on two fronts: with the statewide academic senate that favoured the University of California's campuses at Los Angeles and Berkeley, and with city officials who felt that UCSD should include a full undergraduate programme. UCSD finally opened in 1960 with a postgraduate science focus to support the region's new research economy. "By the time UCSD admitted undergraduates in 1964, it already had a research budget that exceeded that of a typical 100-year-old institution," says Walshok.

By then, the city's civilian scientific community had grown still larger and more diverse (see timeline, page 702). The Scripps Clinic and Research Foundation had been

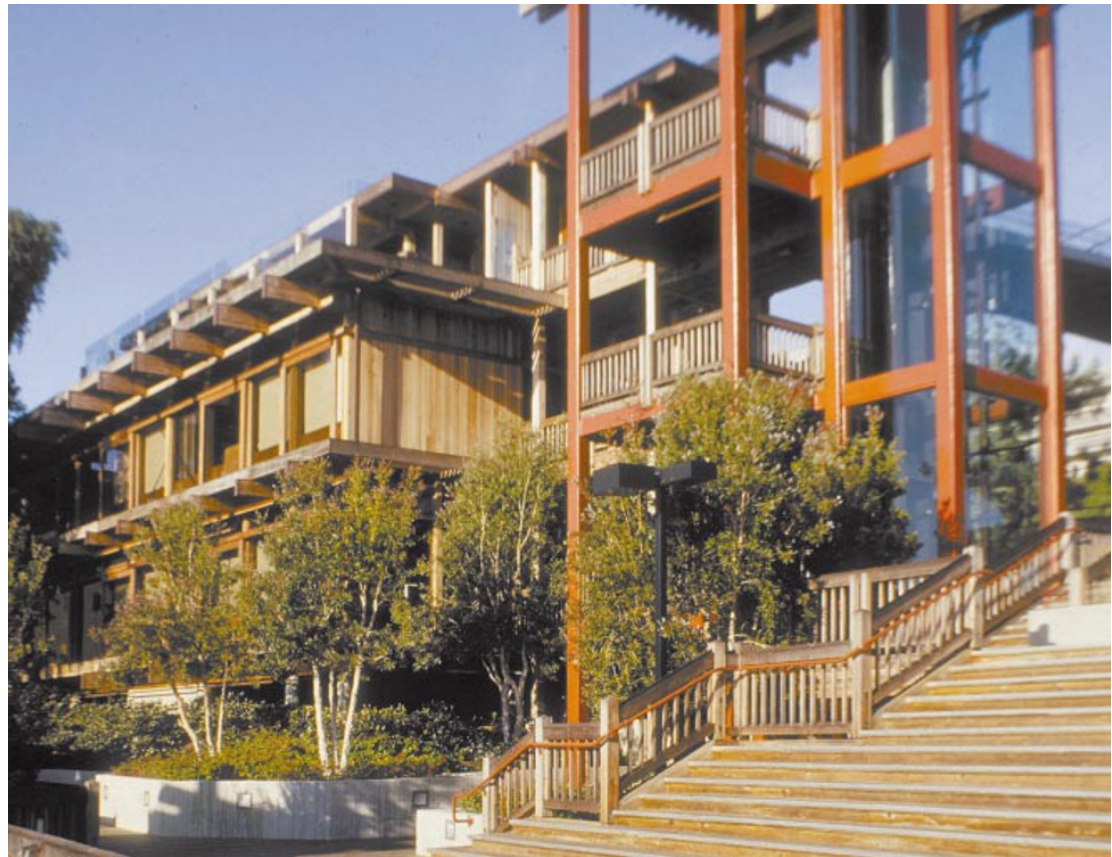

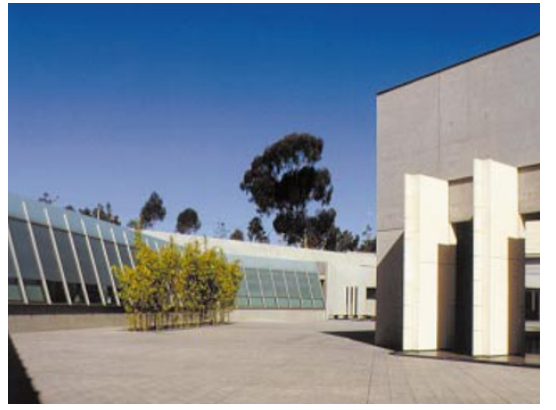

Grand designs: the Neurosciences Institute (above), and the University of California's Geisel Library (top left) and geophysics lab (top) are examples of San Diego's academic environment.

founded in 1955, followed a few years later by biosciences centre the Salk Institute. Already an international hero for his Nobel prizewinning work on the polio vaccine, in 1958 Jonas Salk conceived the idea of founding an institute for sciences and humanities, a worldclass research organization that would attract the top thinkers across a range of disciplines. On the lookout for a suitable site, Salk visited San Diego in 1959, and decided to build his institute there the following year. The city voted in a special referendum to donate an 11-hectare site around the corner from the Scripps Research Institute for the project, and the National Foundation for Infantile Paralysis, which had funded Salk's polio work, pledged money.

By 1963, the first labs were set up in temporary annexes (which house faculty members to this day; see 'A modernist monastery', page 704) and the first generation of resident fellows moved in with Salk, including molecularbiology pioneers Renato Dulbecco, Francis Crick, Salvador Luria and Jacques Monod. Once this illustrious group had taken up residence on the Mesa, the future of San Diego as a scientific juggernaut was sealed.

Other key research centres followed, such as the Burnham Institute (originally called the La Jolla Cancer Research Foundation), and San Diego began to attract significant intellectual capital and funding. But it wasn't until 1968 that San Diego made the crucial connection between academia and commerce. That was when Irwin Jacobs, UCSD professor of computer science and engineering, founded Linkabit, a company that developed military signal-processing equipment and spawned Qualcomm and Leap Wireless — both still have headquarters in San Diego.

Since then, the city's academics have regularly founded companies or served as advisers to them. In 1978, for instance, Ivor Royston 
and Howard Birndorf, both UCSD scientists, founded Hybritech, the first company to commercialize the use of monoclonal antibody diagnostics. "In 1978, I succeeded in making antibodies for leukaemia, but the only way to get this to patients was to move into mass production," says Royston, who now runs local venture-capital firm Forward Ventures.

An ill-fated merger with pharmaceutical giant Eli Lilly in 1986 ultimately resulted in the sale of the then-moribund Hybritech to the medical-instruments company Beckman Coulter at a fraction of its buying price. Many of Hybritech's leading scientists left to form their own companies, such as IDEC Pharmaceuticals and Amylin: "Ultimately, what was bad for Hybritech was good for San Diego's biotech growth as a whole," says Royston.

But it was still some time before San Diego could capitalize fully on its research successes. "Business services were mismatched, focusing on defence rather than innovation," says Tony Nash, research director at New Economy Strategies, a technology-research firm in Washington DC. "San Diego lacked the intellectual-property attorneys, experienced management, and sources of capital necessary for a burgeoning economy." But with the arrival in 1985 of UCSD CONNECT, a universitybased organization that helps researchers develop companies, the science community's commercial engine was shifted up a gear.

The strong relationship between business
Support structure: BIOCOM provides information to San Diego's life-sciences sector.

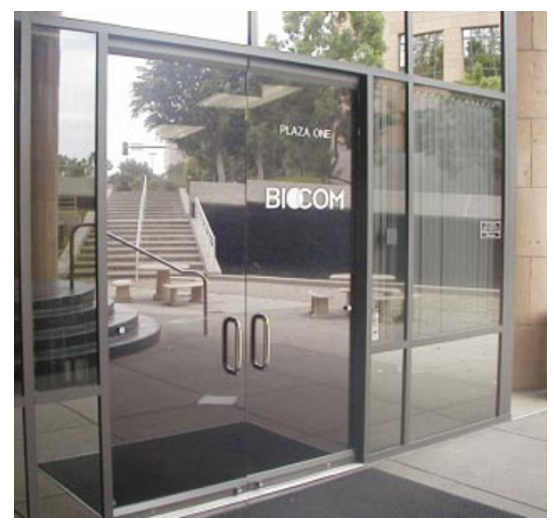

and academia sparked capital investment, and with it grew a corps of support industries around the Torrey Pines Mesa: from realestate brokers, specialist law firms and architects to organizations such as BIOCOM, an Internet information service for the San Diego life-sciences industry. "Companies want to be here because we have the support infrastructure here," says Brent Jacobs, senior vice-president of the life-sciences group at realestate broker Burnham Real Estate. "They no longer have to import builders, architects and other services."

The extra momentum was soon needed. The city's dependence on the military weakened it in the early 1990s when defence cuts led to a loss of 58,000 jobs in the region, says
Julie Meier Wright, president and chief executive of the San Diego Regional Economic Development Corporation. By July 1993, unemployment had risen to $8.4 \%$, whereas the national average had declined to $6.9 \%$, according to a survey by Red Herring Research.

\section{Variety show}

Fortunately for San Diego, the fact that companies as varied as Qualcomm, General Instruments and Stratagene have made a comfortable base for themselves in San Diego owes as much to the region's roots in academic research as to its military history. The combination of decades of research and a strong entrepreneurial spirit launched the biotech, telecoms and informationtechnology companies that would help the region bounce back. "Since the early 1990s, our economy has diversified with industries such as wireless communications and life sciences reaching critical mass," says Wright. Through numerous boom-and-bust cycles, diversification has been key to San Diego's recovery and comparative immunity to economic downturns.

San Diego rising. a, Site of Scripps Institution of Oceanography, 1912 (Scripps Instit. Oceanogr.). b, Navy acquires site for Camp Pendleton Marine base (San Diego Hist. Soc.). c, Nuclear subcritical time-of-flight research facility at General Atomics. (CORBIS). d, UCSD's first graduate (UCSD). e, The Burnham Institute today (Burnham Inst.). f, Genetic engineer's vanity number plate (T. Spiegel/CORBIS). g, Sidney Karin, founder of UCSD's Supercomputer Center with the centre's first Cray computer (San Diego Supercomput. Center). h, Microcirculation lab at UCSD's Dept of Bioengineering (UCSD).

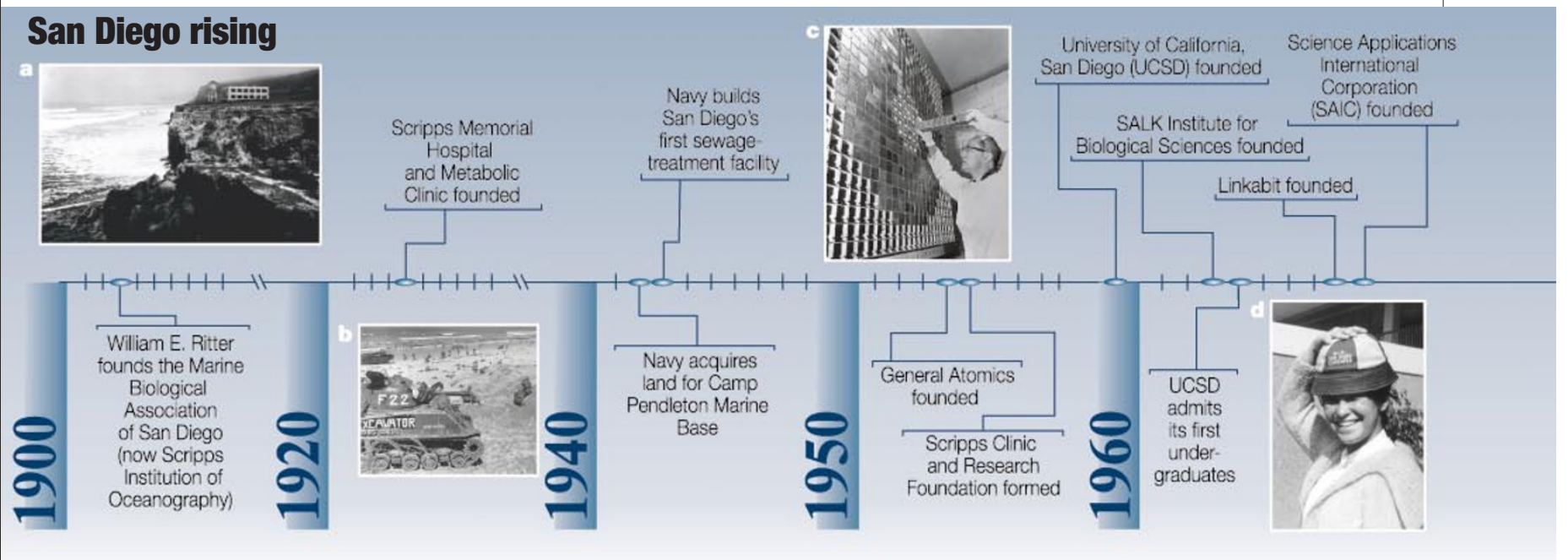




\section{Sun, surf....and cultural evolution}

San Diego may be a major hub for technological excellence, but how does it fare in the cultural stakes? Although it dishes up a staple diet of mainstream opera, ballet and classical music, in addition to more off-the-wall arts offerings, there are moves to bring even more culture to the area.

"In the past we have been considered as culturally challenged," says Victoria Hamilton, director of the San Diego Commission for Arts and Culture, "but over the past ten years we have seen a huge increase in city investment in arts and culture." The commission's budget for 2003 was close to $\$ 10.5$ million, compared with just under $\$ 6$ million in 1993. The area now boasts a thriving arts scene ranging from museums, civic ballet, opera and orchestral groups to more eclectic offerings such as Jean Isaacs' San Diego Dance Theatre and the Sushi performance art venue. The region also has a strong San Diego-Tijuana border arts scene which includes venues such as the Centro Cultural De La Raza and the theatre company Teatro Mestizo.

Although San Diego does not yet boast many huge financial successes, riches reaped from profits and public offerings have already had a positive effect on its cultural scene. Qualcomm donates regularly to arts organizations such as the Museum of Contemporary Art San Diego and the La Jolla Playhouse. Qualcomm co-founder and chief executive Irwin Jacobs and his wife donated

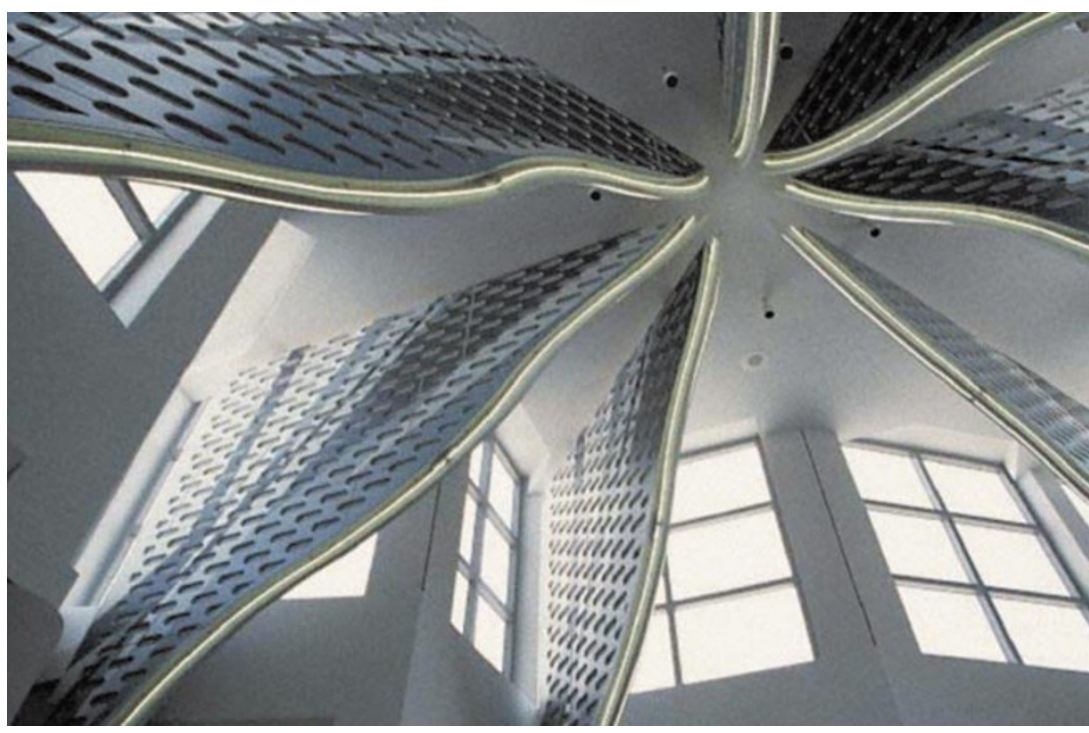

On show: the windows and ceiling of the Museum of Contemporary Art in La Jolla.

$\$ 120$ million to the San Diego Symphony in 2002, a gesture that may, along with the construction of the Walt Disney Concert Hall in Los Angeles,

finally catapault the southern Californian classical music scene into international prominence.

But the lure of culture comes a distant second for scientists and technology professionals considering a move to San Diego. "Science is the main draw," says Anil Seth, a postdoctoral fellow at the Neurosciences Institute, who moved to San Diego from Britain nearly three years ago.

Although the ample sunshine, outdoors lifestyle and culture certainly add to San Diego's allure, Seth adds.

c.v.
In recent years, the rate of change on the Mesa has accelerated. Drawn by the promise of breakthrough drugs and the collegial atmosphere, global pharmaceutical companies have arrived in droves. Pfizer, for example, has set up a 70,000-square-metre research facility. Others, meanwhile, have forged partnerships with smaller biotech firms as happened in Eli Lilly's collaboration with Structural GenomiX. Novartis has an agreement with Scripps in which the company pays the institute \$20 million a year for first rights to choose up to $47 \%$ of ideas for product development until 2006. Over the past five years, major drug companies have committed more than $\$ 1.5$ billion in research and development alliances with San Diego biotech firms, according to a report from the Brookings Institution.

And a new wave of military research has come with a surge in 'biodefence' companies. Defence research has won one of the biggest increases in the 2003 federal R\&D budget, accounting for nearly $55 \%$ of US research spending, up from about $52 \%$ in 2002 . There are now around 75 dedicated biodefence firms in San Diego, and other biotech companies are exploring ways to catch extra defence dollars. The biotech firm Chimerix, for example, was recently awarded a \$36million grant from the National Institutes of Health (NIH) to develop a therapy for smallpox, classified as a 'category A' bioterrorism threat by the federal government.

But general investment in the science and technology industry and academic research
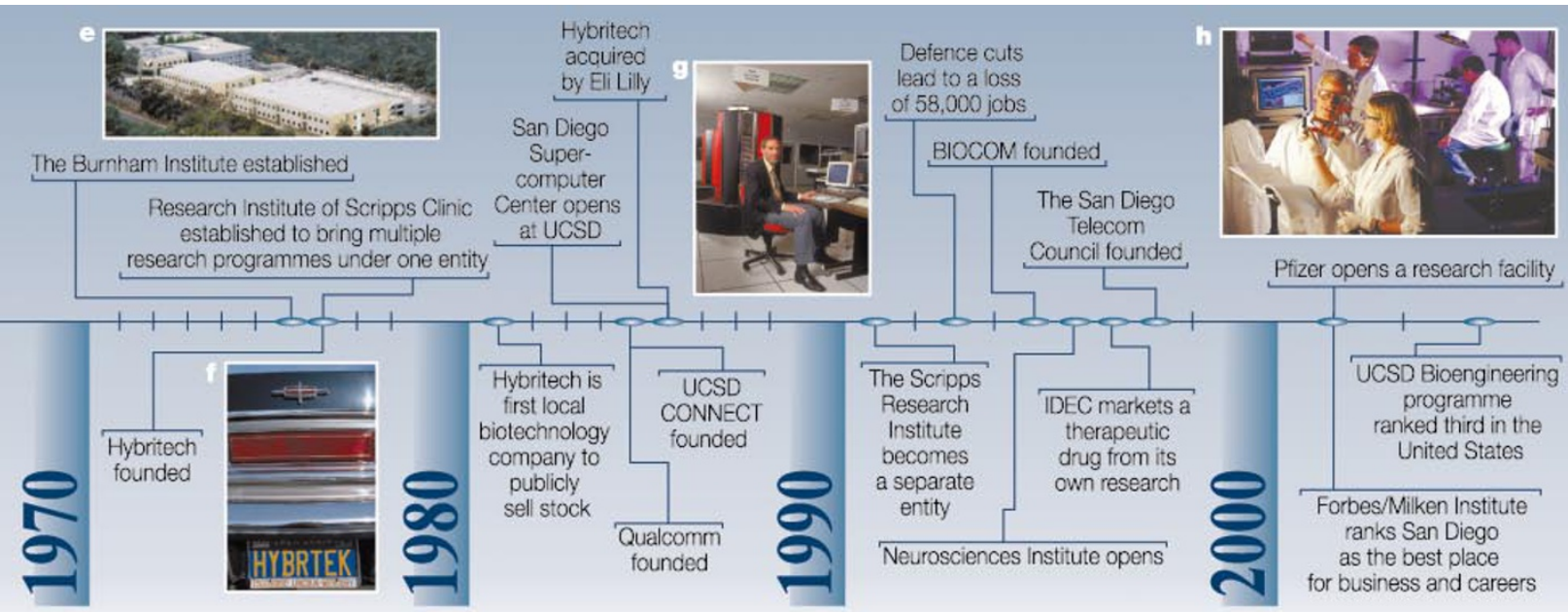

Pfizer opens a research facility

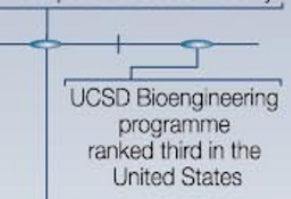

Forbes/Milken Institute

ranks San Diego

as the best place for business and careers 
is down. According to Red Herring Research, venture-capital investment decreased by more than $30 \%$ between 2000 and 2001. "We can't fund science for its own sake," says Royston. "A few years ago, early-stage research could be funded, but financing is generally only available today for companies on their way to developing products."

The changing investment scene, and the huge California state budget deficit of at least $\$ 10$ billion, is also weighing heavily on academic organizations. "The depression within the industry has transferred the burden of translational research to academic institutions," says Ronald Evans, a long-serving scientist at the Salk Institute. "But our forte isn't commercialization, it's discovery."

With some of San Diego's academic institutions struggling to fulfil their basic research mandate in these tougher times, many researchers have begun to look for ways to bridge the funding gap. Ken Chien, director of UCSD's Institute of Molecular Medicine, believes that there will be an increasing focus on translational research - working at the interface between pure biology and its application in clinical treatments. Chien envisions increasing the number and output of physician-scientist training programmes, developing private-sector partnerships and establishing interdisciplinary teams with a range of academic and commercial skills.

San Diego's high-tech specialism has grown over many years from a unique confluence of geography, military spending, world-class academic centres and the connections fostered between the local business and research communities. "It's taken decades for San Diego to reap the benefits," says Nash. "Other regions are trying to take short-cuts but it's hard to develop excellence quickly."

San Diego faces further challenges in the coming years: increasing congestion, inadequate infrastructure — such as a lack of affordable housing — and only one small airport (see 'Good neighbours', page 690). But despite growing pains, its reputation as a high-tech haven remains high. "Everybody wants to come here," says Evans, strolling across the Salk Institute's exquisitely designed plaza towards his cosy, naturally lit office. Its previous tenant was Jonas Salk himself. "I've been here for 25 years and I don't feel much of a push to leave."

Chloe Veltman is a freelance writer in San Francisco.

\section{A modernist monastery}

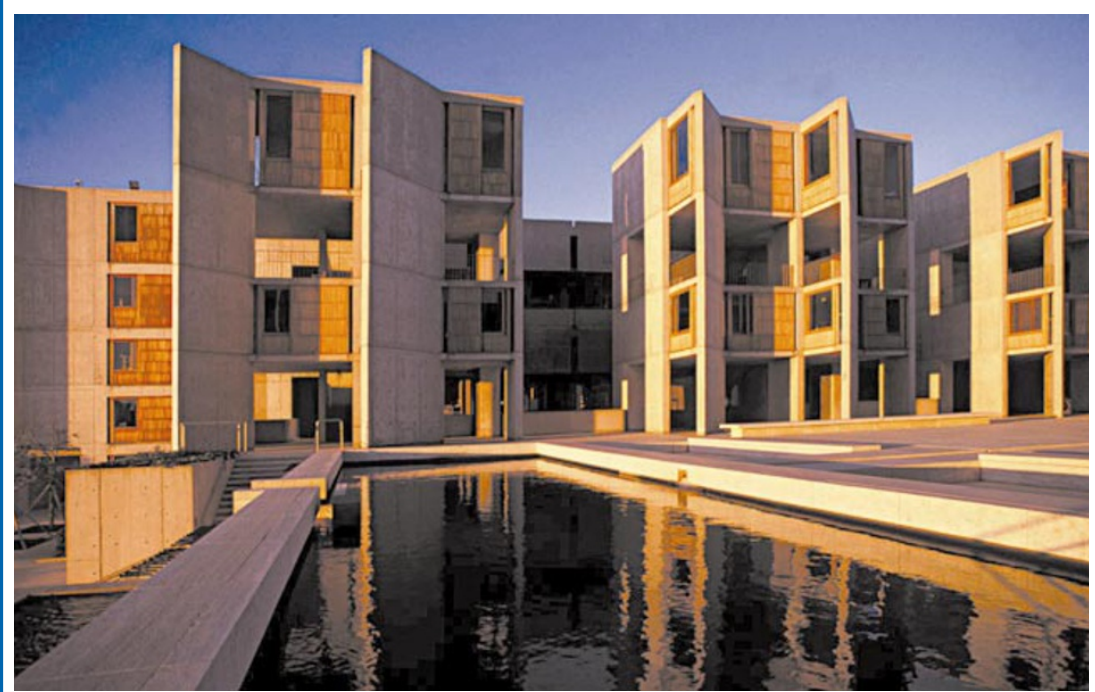

The Salk Institute helped to set a high standard of architecture for San Diego's research institutes.

Torrey Pines Mesa is the most prestigious area of San Diego's high-tech hub, attracting an élite workforce with its sweeping views of the Pacific, plunging cliffs, and stunning architecture. The space is aesthetically anchored by the Salk Institute, designed by Louis Kahn, with its breezy plaza, private study towers and secluded labs. Other structures also strive to set the tone, including the sculptural Neurosciences Institute designed by New York architecture firm Tod Williams Billie Tsien \& Associates in 1996. "The Salk, Scripps and

the Neuroscience Institute have set a standard that all buildings seek to follow," says San Diego architect Alison Whitelaw.

Concrete, glass, water features and elegant modernist lines dominate the most notable buildings situated on the Mesa, with architects responding to the natural surroundings and climate. Inspired by the gaping canyons and spiralling vistas, architects have incorporated windows and open spaces into their designs to make the most of the views.

At the Salk Institute, a slim channel of water spans the entire length of the broad central plaza at the heart of the complex. Designed to flow from east to west, or, as Ronald Evans, a scientist at the institute, puts it, "from the known world to the unexplored frontier", the channel is directly in line with the Sun as it traces its descent into the Pacific Ocean, drenching the plaza with late afternoon light and turning the channel into a fiery ray. Salk scientists are equally proud of the building's interior. The labs display the usual clutter of glassware and equipment, but they are airy and open-plan, with desks arranged in a long line along one side of the room so everyone can see each other. "The architecture reflects the idea of the Mesa as a monastic setting," says Whitelaw. "Architects are engaged in creating environments that allow people to be more productive."

But for Salk scientist Joseph Ecker, the surrounding landscape is more awe-inspiring than the buildings themselves. Ecker, a plant molecular biologist, works in the old temporary annex buildings that once housed Salk's founding scientists, while the Louis Kahn building was being built. Standing on a bluff overlooking a favourite hang-gliding spot, the annex, with its peeling linoleum and sun-bleached walls, has a ramshackle charm, partly because of the vistas on its doorstep, and partly because of the sense of history and purity of purpose that permeates the concrete walls. Here, natural and artificial structures inform each other. "The juxtaposition of the two is what I think most people find so striking," says Ecker. 